\title{
Bisphenol A may reduce the efficacy of androgen deprivation therapy in prostate cancer
}

\author{
Janet K. Hess-Wilson
}

Received: 10 November 2008/Accepted: 1 April 2009/Published online: 17 April 2009

(C) Springer Science+Business Media B.V. 2009

\begin{abstract}
Individuals diagnosed with specific diseases may represent subpopulations with heightened sensitivity to environmental compounds. This may be due to their diseasemediated molecular milieu and/or the interference of environmental compounds with pharmaceutical drug targets. Prostate cancer represents a significant clinical challenge in the United States. If the disease becomes advanced, standard therapies are ineffective, leading to high rate of patient morbidity and mortality. Understanding the complex reasons for therapeutic resistance is critical for improving the life expectancy for patients with this cancer. Recently, it has been identified that common somatically derived genetic mutations that arise following the selective pressure of standard prostate cancer treatments may facilitate sensitivity to environmental contaminants. These somatic mutations within the androgen receptor allow the estrogen mimic, bisphenol A (BPA), to bind and activate the receptor, resulting in increased proliferation and tumor growth in the presence of the traditional therapy regimen for prostate cancer. In an in vivo xenograft model of prostate cancer, low level exposure of BPA was sufficient to reduce the efficacy of treatment. Herein, the possible effect of BPA on prostate cancer treatment and disease management for humans is explored as an example of environmental endocrine disruptor exposure reducing the efficacy of disease management. These data lend support to the hypothesis that
\end{abstract}

J. K. Hess-Wilson ( $\square)$

US Environmental Protection Agency, Office of Research and Development, National Center for Environmental Assessment (MS A-110), 26 W. Martin Luther King Dr., Cincinnati, OH 45268, USA

e-mail: hess-wilson.janet@epa.gov environmental exposure to select compounds may interfere with specific therapeutic regimens.

Keywords Androgen receptor - Bisphenol A . Endocrine disrupting compound $\cdot$ Prostate cancer

\section{Introduction}

Prostate cancer is the second leading cause of cancerrelated deaths among United States males and the most commonly diagnosed malignancy in this country. In 2008, it is estimated that over 28,000 men would die of this disease in the United States [1]. Patients with organ-confined prostate cancer can be effectively treated through radical prostatectomy or radiation therapies; however, most invasive tumors of the prostate are completely resistant to general cytotoxic therapies [2,3]. As such, the mainline therapeutic intervention for disseminated disease is androgen deprivation therapy (ADT), which relies on the androgen dependence of this tumor type [4-6]. ADT is initially effective, as almost all patients undergo a period of remission, manifested by tumor cell death and reduced tumor burden. However, the majority of patients develop ADT-resistant tumors, for which no effective or curative treatment has been identified [7]. Therefore, identifying the factors that influence ADT efficacy is imperative to improve the outcome of prostate cancer treatment and increase patient survival of this deadly disease.

ADT is designed to ablate androgen receptor (AR) function. AR is a nuclear hormone receptor and functions as a ligand-dependent transcription factor. Androgen (testosterone and the high affinity dihydrotestosterone, DHT) binds to $\mathrm{AR}$ and stimulates receptor homodimerization and rapid translocation to the nucleus. Activated nuclear AR 
binds to androgen response elements (AREs) in the promoter regions of target genes and recruits co-activator molecules to initiate gene transcription. Activation of AR results in numerous biological outcomes, dependent on cellular context, including secretion of key proteases and cellular proliferation. Hence, ADT aims to inhibit cellular proliferation by preventing AR activity either through the use of direct AR antagonists or through the inhibition of ligand (androgen) synthesis (Fig. 1a). At the cellular level, ADT triggers a cascade of events leading to either programmed cell death or cell cycle arrest. Clinically, efficacy of ADT is demonstrated by tumor remission; however, recurrent ADT-resistant tumors typically arise within a median of 2-3 years [7]. Development of ADT-resistance is attributed to restored AR activity and consequential resumption of tumor growth. Several molecular mechanisms have been identified and linked to AR reactivation within ADT-resistant tumors. In up to an estimated $25 \%$ of therapy-resistant tumors, ADT is known to select for mutations of the AR ligand binding domain that alters the conformation of this domain and allows binding and activation by other steroid hormones (e.g., estrogen, cortisol, progesterone) or even therapeutic AR antagonists (e.g., flutamide) [8-11]. Other examples of alteration in $A R$ action include AR overexpression, ligand-independent AR activation, or overexpression of AR co-activators [reviewed in 12]. Given the biological requirement of AR activation for prostate adenocarcinoma cell growth, it is evident that mechanisms of enhancing AR action can have substantial effects on prostate cancer development and treatment.

Several environmental and industrial compounds demonstrate the potential to mimic, alter, or block endogenous hormone action and are generally identified as endocrineactive compounds. There is an increased interest in elucidating their biological effects and impacts on human health. Several endocrine-active compounds have been hypothesized to alter androgen action and/or reproductive organ growth and development, including the prostate. Most notably, some studies have suggested that in utero or neonatal exposure to compounds such as bisphenol A (BPA), polychlorinated biphenyls (PCBs), or hexachlorobenzene (HCB) increases prostate size or weight, thus suggesting that these agents could influence early growth patterns [13-18]. Recent bioassays have shown that developmental exposure to BPA increases susceptibility to prostate cancer in adult rats [19-21], and numerous studies have demonstrated the adverse effect of BPA on prostatic cell proliferation and architecture [14, 15, 18, 22, 23]. However, a uniform understanding of endocrine-active compounds on prostate development and cancer incidence has yet to be fully elucidated, and many observations remain highly controversial. Several recent publications review the relationship between BPA exposure and prostate disease [24-27].

Recent reports have highlighted a novel interaction between specific endocrine-active compounds and select prostate tumor-derived mutant ARs. It has been shown that environmental compounds, such as BPA $(1 \mathrm{nM})$ and dichlorodiphenyldichloroethylene (DDE; $10 \mathrm{pM}$ ), can activate tumor-derived mutant ARs and induce AR-dependent proliferation of the cancer cell in the absence of natural mitogenic stimulus [28-30]. These studies shift the attention from compounds causing, or increasing the susceptibility to, prostate cancer to assessing the impact of these agents on the progression and treatment of established disease. These data suggest that although a prostate cancer patient may be using pharmacologic means to reduce AR action, the presence of endocrine-active compounds may be reducing the efficacy of therapy by inducing proliferation of the cancerous cells. It is essential to define the relative risk of environmental exposure to endocrine-active compounds in patients undergoing ADT for prostate cancer. These analyses may impact the human health risk assessments for such compounds, as highly susceptible subpopulation of humans may be identified and necessitate consideration for environmental risk management. Herein, we will evaluate the hypothesis that BPA may negatively impact the success of prostate cancer ADT, including a discussion of BPA exposure levels, a description of the hypothesized mode of action, and the overall likelihood that BPA may be a health concern for prostate cancer patients and disease management.

\section{Bisphenol A exposure}

Bisphenol A (BPA) is an industrial non-planer compound used as a component of polycarbonate plastics, epoxy resins, and dental sealants [31]. The epoxy resins are used as coatings for food cans and metal jar lids, as general protective coatings, finishes, adhesives, and as coatings for PVC pipes. The polycarbonate plastics are used in compact disk manufacturing, household appliances, food packaging, and plastic bottles with high impact strength, hardness, and toughness. Due to the vast increase in BPA-containing products (notably polycarbonate plastics), manufacture of and exposure to BPA has dramatically increased in the United States within the past decade [32]. Currently, onethird of all BPA is manufactured in the United States, estimated close to $1.1 \times 10^{6}$ metric tons (over 1,100 million $\mathrm{kg}$ ) annually [32].

Due to the widespread use of BPA, the potential for human exposure is significant. Most human exposure to BPA comes from contamination in food caused by migration from containers made with BPA [reviewed in 31, 33]. BPA has been detected in canned vegetables, fish, 

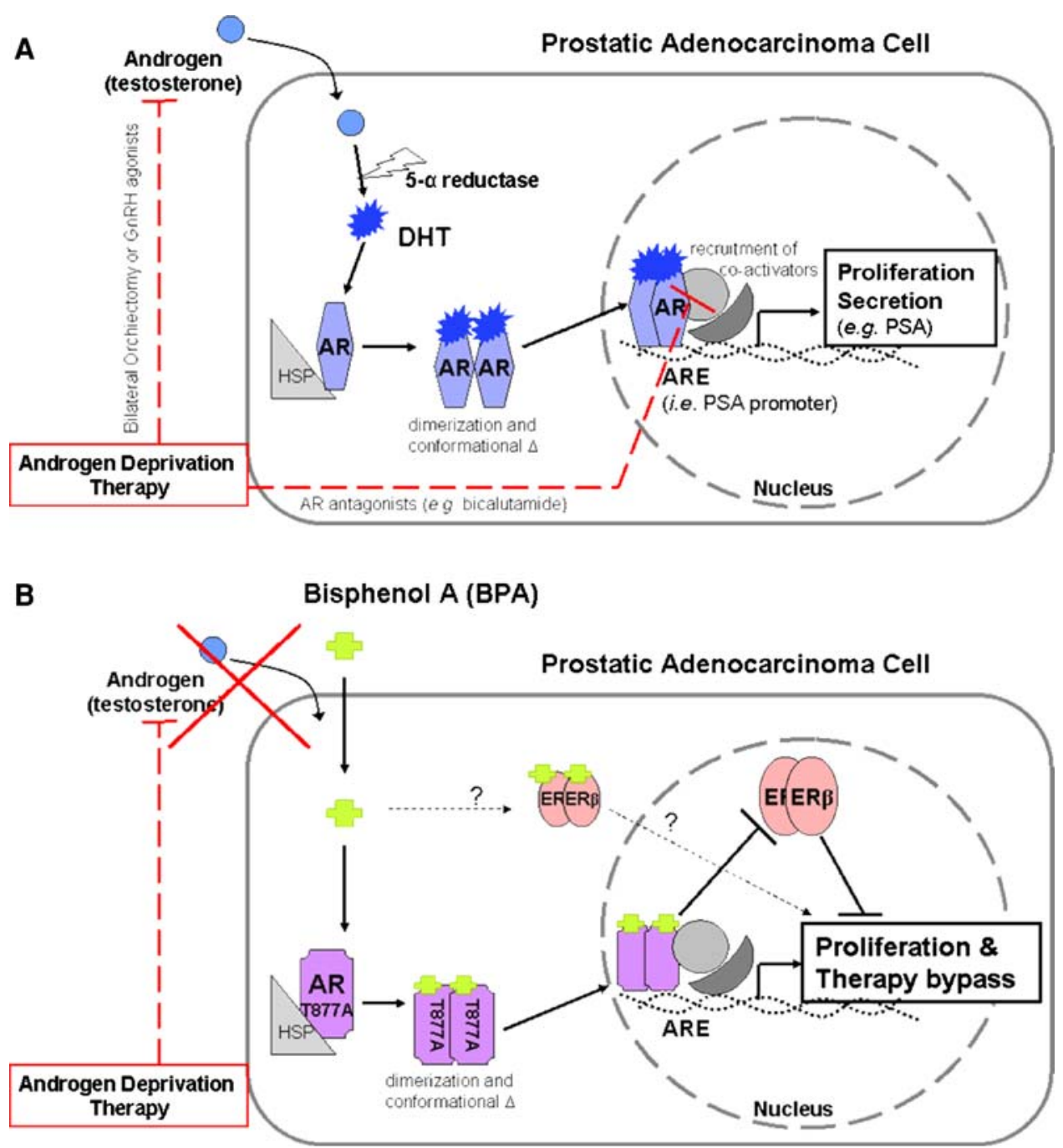

Fig. 1 a Schematic illustrating the molecular action of androgen and the impact of standard prostate cancer therapies in a prostatic adenocarcinoma cell. Androgen from the blood stream is able to diffuse into the prostatic epithelial cell where it is converted to dihydrotestosterone $(D H T)$ by the enzymatic action of 5 - $\alpha$-reductase. DHT is a high affinity ligand for the androgen receptor $(A R)$, which upon ligand binding, is disassociated from heat shock proteins (HSP) in the cytoplasm of the cell. Ligand bound AR undergoes conformational changes, dimerizes and then translocates into the cell nucleus. Once inside the nucleus, with the assistance of co-activator molecules, AR binds to target gene regulatory regions (ARE's: androgen response elements) such as prostate specific antigen (PSA). AR transcriptional targets control cellular function such as proliferation and secretion. Standard therapies for prostate cancer are aimed towards inhibiting the signaling of androgen and AR. Androgen deprivation therapy $(A D T)$ uses compounds such as gonadotropin releasing hormone $(G n R H)$ agonist to inhibit the synthesis of testosterone. Direct AR antagonists, such as bicalutamide, bind to

meat, diary, and infant formula [34-36]. Several studies have detected migrated BPA levels between 2 and $87 \mathrm{ng} / \mathrm{ml}$ following heating of cans to temperatures used in the processes of canning food [reviewed in 31]. BPA
$\mathrm{AR}$ and cause transcriptional repression. Both methods of ADT prevent AR-dependent proliferation. b Illustration of the impact of bisphenol A (BPA) on androgen receptor signaling. Due to the selective pressure of ADT, mutant ARs arise that are amenable to activation by alternate ligands, such as BPA. BPA binds to mutant ARs (e.g., AR-T877A), causing release from heat shock proteins, dimerization and translocation into the nucleus. BPA bound ART877A binds to androgen responsive elements and induce transcription of target genes, leading to cellular proliferation. Additionally, there is a putative link between BPA cellular effects and the estrogen receptor beta $(E R \beta)$ signaling within a prostate epithelial cell. At this point, it is unknown whether $\operatorname{ER} \beta$ and AR function together to drive proliferation, or if activated $\mathrm{ER} \beta$ can elicit proliferation on its own. It is known that activation of mutant AR is a necessary event preceding $\mathrm{BPA}-$ mediated proliferation. In the presence of ADT, BPA is able to induce cellular proliferation and potential therapeutic bypass for prostate cancer cells

migration can also be affected by the storage time of canned foods, and migration from can coatings may differ between manufacturing plants and methods and/or types of internal coating materials. BPA migration from polycarbonate 
plastics has also attracted much public attention. Several studies have showed relatively low levels of BPA leaching from new polycarbonate bottles; however, levels were up to 10 -fold higher from used and/or scratched bottles [37]. It is believed that due to degradation of the plastic polymers, BPA elution is increased with age and wear. The carbonate linkages between polymers are initially stable, but can hydrolyze upon exposure to hot water or alkaline $\mathrm{pH}$, leading to migration of BPA from plastics after washing and sterilization, as well as with general wear and use [31].

There have been numerous attempts to identify the amount and extent of BPA exposure to the human population. A recent study by Calafat et al. [38] found that up to $95 \%$ of their demographically diverse sample of the United States adult population had detectable BPA in their urine, with concentrations reported to range in the nanomolar range (mean concentration in urine of $1.33 \mu \mathrm{g} / \mathrm{l}$ ). Additionally, several other studies have reported adult BPA levels in the nanomolar range (using both serum and urine analyses), with nearly $100 \%$ of sample populations having detectable BPA or BPA metabolites [reviewed in 39].

Several attempts at calculating the daily exposure levels of BPA have been made. Although diverse in geographical location, sample size and demographics, and method of calculation, all estimates are relatively consistent. On the basis of several congruent studies, the daily intake of BPA can be assumed to be $<1 \mu \mathrm{g} / \mathrm{kg}$ body weight/day [31]. Given the increasing usage of BPA and the body of literature that has quantified BPA in human serum and/or urine, it is plausible that the majority of adult males in the United States are exposed to detectable amounts of BPA. Therefore, it is a legitimate concern as to whether BPA has adverse affects on prostate cancer management and treatment efficacy, at doses that the average adult male may encounter.

\section{Bisphenol A impact on prostate cancer treatment: in vivo evidence}

There is currently no human epidemiological or clinical studies assessing the impact of endocrine disruptive compounds, such as BPA, on prostate cancer management; however, recent murine in vivo studies directly examined the impact of low dose (within the range reported in human serum) BPA on prostate cancer disease progression and treatment. There is a paucity of experimental models with which to study prostate cancer; however, the LNCaP xenograft tumor model closely mimics standard disease progression and ADT cellular processes. LNCaP cells are one of the few human prostate cancer cell lines that retain the characteristics of early stage disease; they are androgen responsive and retain AR expression [40, 41]. Importantly, the LNCaP cell line harbors a BPA-responsive mutant AR, AR-T877A [29]. The most common mutational "hot spot" of the AR lies within the ligand binding domain, containing codon 877 . Not only has it been estimated that up to $25 \%$ of advanced disease harbors mutant AR, Gaddipati et al. [42] determined that codon 877 mutations are the most frequent mutations detected in advanced prostate cancer. This provides strong support for the relevance and applicability of the LNCaP model to study the impact of BPA on prostate cancer treatment. Briefly, male nude mice were subcutaneously injected with LNCaP cells [43]. Once tumors formed on the flanks of the male mice, mice were castrated to deplete endogenous androgen and mimic ADT. Mice were then randomized into two cohorts, one receiving subcutaneous placebo time-release pellets and the other receiving subcutaneous BPA 21-day time-release pellets. These pellets were manufactured with $12.5 \mathrm{mg}$ of BPA and through serum analysis, it was shown that the presence of these pellets resulted in a continual release of BPA into the mouse circulatory system, steadily declining from approximately $27-2 \mathrm{ng} / \mathrm{ml}$ over 28 days. This methodology has the caveat that human exposure to BPA is primarily through oral ingestion, and therefore, BPA goes through first pass metabolism in the liver, where it is estimated that $95 \%$ of ingested BPA is metabolized to the glucocoronidated form (BPA-monoglucuronide, BPAG). BPAG has been found to contain no endocrine disrupting or adverse effects [44, 45]. Wetherill et al. [43] did not measure BPAG levels in serum; however, the level of BPA in the serum of mice implanted with the time-release pellets did fall within the range of BPA detected in adult human serum. This methodology, however, still leaves some uncertainty to the effect of the route of administration and increases the uncertainty for direct correlation to the human paradigm of BPA exposure. Conversely, this methodology reduces the uncertainty concerning rodent versus human metabolic processing of BPA, and assumes that since the concentration of free BPA in the blood fell within the range reported in humans, the human prostatic xenograft would be exposed to equivalent levels of BPA as a human prostatic tumor.

The salient observation of Wetherill et al. [43] was that low levels of BPA had a negative impact on the disease progression and efficacy of therapy in the murine xenograft model of prostate cancer. The environmentally relevant levels of BPA during mimicked ADT in the mice, resulted in an increase in a AR target gene product (prostate specific antigen, PSA), larger xenograft tumor volumes, increased cellular proliferation in the tumors, and a shorter time to therapy failure compared to placebo controls. The implications of this finding for the human population are significant, given the inevitable and short time to therapy failure and no effective therapeutic strategies for advanced 
disease. These reports provide the impetus to fully examine whether exogenous compounds could negatively interfere with prostate cancer treatment and disease management.

\section{Bisphenol A impact on prostate cancer treatment: mode of action}

There is in an vitro evidence indicating plausible modes of action of BPA-mediated reduced therapeutics efficacy for prostate cancer [28-30]. Multiple lines of evidence indicate that the key event resulting in BPA-facilitated therapeutic bypass of prostate cancer cells is the binding to and activation of tumor-derived mutant ARs by BPA, resulting in BPA:AR complex-mediated cellular proliferation [28-30, 46].

Human prostate cancer cell lines were used to study the mechanism by which BPA impacted prostate cancer progression. Upon androgen withdrawal (switching the cells to culture conditions deprived of steroid hormones), LNCaP cells undergo growth arrest in G0; however, cell cycle can be re-initiated and regulated by adding mitogenic levels of androgen. Therefore, the ability of BPA to activate an endogenous AR within the molecular context of human prostate cancer cells was tested in this tissue culture system. When BPA was added to these cells in the absence of steroid hormones, BPA facilitated cell cycle entry and androgen-independent proliferation. The mitogenic capacity of BPA was shown to require AR-T877A activation; blocking the receptor with a pure antagonist diminished the proliferative response. Additionally, it was determined that the mitogenic dose response was biphasic or resulted in an "inverted U" dose response, typical of hormone and hormone receptor mediated proliferation, [47] and $10^{-9} \mathrm{M}$ $(1 \mathrm{nM})$ was the optimal mitogenic dose of BPA. This finding is salient, as nanomolar concentrations of BPA are well within the estimated ranges of human exposure [39], as detected in serum and urine samples. However, toxicokinetics and the exact tissue concentrations of BPA are not taken into account in this correlation, and further investigation of internal tissue dosimetry would greatly enhance this area of research.

In a further study, Wetherill et al. [28] explored the ability of BPA to activate additional mutant ARs. It was shown that AR-negative or wild-type AR expressing prostate cancer cells were refractory to BPA-mediated effects. Additionally, BPA was able to activate other tumor-derived AR mutants, thus expanding the potential influence of BPA on prostate cancer. Combined, these data begin to associate BPA as an inappropriate and effective mitogen for prostate cancer cells, whose mode of action is mediated through activation of tumor-derived mutant ARs, in the absence of endogenous, natural ligand (Fig. 1b). These data support the hypothesis that endocrine-active compounds, such as BPA, could possibly contribute to therapeutic bypass in patients with advanced prostate cancer via mutant AR-mediated mitogenesis.

Although a link has been established between environmentally relevant levels of BPA and the bypass of standard ADT for prostate cancer using both in vivo and in vitro models, much effort needs to be focused on elucidating the exact mechanism of BPA action in prostate cancer cells. Activation of tumor-derived AR mutants has been identified as a key event; however, the precise mechanism of AR proliferative regulation is, itself, poorly understood. Experiments comparing the transcriptional signature profiles of BPA-treated and DHT-treated prostate cancer cells have attempted to elucidate the genetic mechanisms of BPA-mediated proliferation and have confirmed BPAmediated induction of AR target genes [46]. Interestingly, BPA treatment also resulted in downregulation of estrogen receptor beta $(\mathrm{ER} \beta)$, not seen with DHT [46]. This observation is significant because $\mathrm{ER} \beta$ is thought to be required for AR-mediated proliferation of androgen-dependent prostate cancer cells [48, 49]. A hypothesis emerges wherein low level BPA activates tumor-derived AR mutants, and through ill-defined mechanisms, decreases expression of ER $\beta$. Reduced $\operatorname{ER} \beta$ allows for enhanced proliferation of prostate cancer cells, even in the absence of androgen (Fig. 1b). ER $\beta$ has been shown to be important in prostate cancer disease progression, as numerous clinical observations of prostate cancer specimens show a clear reverse correlation between $\operatorname{ER} \beta$ levels and prostate cancer stage [50-53]. Further work needs to be focused on examining both the molecular link between AR-mediated proliferation and $\mathrm{ER} \beta$ signaling, and the requirement of $\mathrm{ER} \beta$ for the adverse effects of BPA in the prostate.

In summary, significant evidence indicates that in the absence of androgen (i.e., during standard therapy for prostate cancer, ADT) environmentally relevant levels of BPA can bind and activate common tumor-derived AR mutants which is known to arise during prostate cancer disease progression. Activation of the AR results in ARdependent proliferation of prostate cancer cells, potentially converging on ER $\beta$ signaling pathways. BPA-mediated proliferation may lead to bypass of ADT and reduced time to therapeutic failure, as demonstrated in murine xenograft tumor models. It remains plausible that exposure to BPA may have a detrimental impact on prostate cancer management (Fig. 2). Clinically, options exist for remediation of ubiquitous exposure to BPA or other endocrine-active compounds in prostate cancer patients. Use of the direct AR antagonist, bicalutamide, results in the impediment of AR-mediated proliferation in the presence of BPA [28, 29]. Therefore, bicalutamide administration may effectively block this pathway. A shift in the clinical treatment paradigm toward increased use of direct AR antagonists (as 
Fig. 2 Diagram of the events leading to reduced therapeutic efficacy from exposure to environmental endocrine active compounds. When a patient first presents with prostate cancer, the adenocarcinoma cells express the wild type androgen receptor and are reliant upon androgen for mitogenic signaling. As such, androgen deprivation therapy $(A D T)$ is utilized to exploit the dependence on androgen and adenocarcinoma cells undergo programmed cell death resulting in tumor remission. Ultimately however, the AR becomes somatically mutated and tumor growth is resumed. Cells expressing mutant ARs are potentially sensitized to select endocrine active compounds and are stimulated to grow and survive even in the absence of androgen. This cellular utilization of endocrine active compounds as mitogenic signals, may lead to exacerbated adenocarcinoma cell growth and a resistance to therapeutic options



\section{Hormone dependent adenocarcınoma cells undergo cell death Tumor remission.}

\section{rise to tumor expressing somatic ally mutated AR.}

Therapeutic selection gives

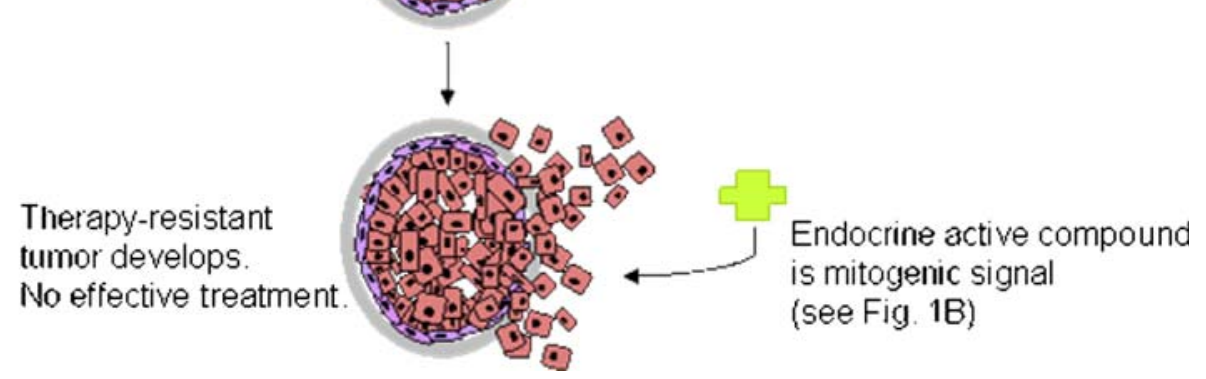

opposed to targeting androgen synthesis pathways) would reduce the risk of endocrine-active compound-mediated therapy bypass. While it is clear that alternative strategies are needed to improve the survival outcome for patients with advanced stage prostate cancer, expanding the time to therapy failure and increasing the effectiveness of current treatment modalities would be well received by prostate cancer patients.

\section{Future needs}

The hypothesis that disease management may be negatively impacted by environmental exposure has important clinical and human health risk assessment implications. Conclusive evidence is still needed to fully define the impact of endocrine disrupting compounds, such as BPA, on prostate cancer disease management; additional rodent studies and epidemiology evaluation of human populations may provide further insights. Furthermore, toxicokinetic and physiologically based pharmacokinetic research would significantly enhance the understanding of internal dose response and target tissue dosimetry of BPA in the prostate.

Patient education about the dangers of exposure to environmental endocrine-active compounds can be increased through public health and community efforts. Not using old and/or worn plastic bottles, not leaving plastic drinking bottles in places of extreme heat (i.e., inside cars during high temperature days), not microwaving food in plastic containers and reducing canned food consumption are examples of measures that are reported as ways to reduce the prostate cancer patient's potential for BPA exposure. Increasing the awareness of compounds that may negatively interfere with standard therapy allows for the clinicians to prescribe more effective treatments and for the patients to improve the therapeutic effectiveness via simple lifestyle changes. Exposure to BPA represents an example of an environmental endocrine disruptor with possible interference of disease management, and it highlights the need for further investigation into the impact of 
other endocrine-active compounds on hormone-regulated disease treatments.

\section{Are other environmental contaminants inferring with disease management?}

The question remains as to whether BPA interference with late-stage prostate cancer treatment is an anomaly or whether other environmental contaminants might negatively impact this and/or other disease management paradigms. It is well known that there are numerous ubiquitous compounds in the environment which are hypothesized to mimic estrogen action. It is unknown whether any of these may elicit similar proliferative responses within the context of tumor-derived AR mutant expression in prostate cancer cells.

An obvious analogy to the BPA and prostate cancer story is the situation of endocrine-active compounds and breast cancer treatment. Breast cancer treatment options are significantly different from prostate cancer operation; however, it is still a disease that is, at least simplistically, regulated via estrogen and the estrogen receptor (ER). Many molecular alterations have been identified in breast cancer cells, vastly increasing the molecular variability amongst patients. The standard therapeutic strategy for breast cancer entails the use of tamoxifen, a direct and potent ER $\alpha$ antagonist, which effectively blocks all ER signaling. As such, even the presence of estrogenic endocrine-active compounds would likely not be able to bypass the effects of tamoxifen [54]. However, due to the side effects (increased osteoporosis and incidence of uterine cancer) of tamoxifen use, there is a push to utilize other treatment strategies, such as aromatase inhibitors [55-57]. Aromatase inhibitors block the metabolism and formation of estrogen, thereby reducing the estrogenic signaling capacity or ER, however, leaving the ER intact and fully functional. This molecular context may enable estrogenic environmental compounds able to bind to and activate ER $\alpha$. Particularly of importance, is the fact that often ER $\alpha$ expression is increased in breast cancer tumors [58], so even so-called weak estrogenic endocrine disrupting compounds may be able to mediate a significant proliferative response in the absence of endogenous estrogen. Significantly, a recent study showed that environmentally low levels of BPA are able to interfere with chemotherapeutic agents in both ER $\alpha$-positive and -negative breast cancer cell lines, possibly by increasing anti-apoptotic factors [59].

Thyroid diseases, polycystic ovarian syndrome, and uterine cancer are examples of other diseases that are regulated by hormone action and treatment strategies often manipulate endocrine signaling. It is possible that clinical management and treatment of these diseases may also be amenable to influence by endocrine-active compounds in the environment. There may also be other drug targets or specific diseases that render patients more susceptible to environmental contaminants, which warrant further exploration into drug-environmental compound interactions and disease molecular state-environmental compound interactions.

The molecular changes that occur within organs due to either the presence of disease or the therapeutic strategies utilized are appreciated by molecular biologist, pharmacologist and clinicians. However, these specific molecular contexts are rarely challenged with environmental insult. Moreover, it is recognized that the efficacy of disease treatment is often less than would be estimated based on molecular biology. Certainly, population diversity and genetic polymorphisms account for the wide variation in the successful management of select diseases. However, it is also plausible that the presence of environmental compounds may be interfering with drug action and reducing the efficacy of therapy. Detailed and specific data on environment: disease-mediated molecular milieu may be valuable information for human health risk assessments, as patients may represent subpopulations of individuals more highly susceptible to specific environmental insult.

Acknowledgments The authors would like to thank Dr. Jay Zhao and Dr. Michel Stevens (US EPA, ORD, NCEA), and Dr. Ray Yang (Colorado State University) for consultation and guidance throughout the manuscript development and US EPA, ORD, National Center for Environmental Assessment, colleagues who reviewed the manuscript, Dr. Belinda Hawkins and Dr. Debdas Mukerjee.

\section{References}

1. Jemal A, Siegel R, Ward E, Hao Y, Xu J, Murray T et al (2008) Cancer statistics, 2008. CA Cancer J Clin 58(2):71-96. doi:10.3322/CA.2007.0010

2. Zeliadt SB, Ramsey SD, Penson DF, Hall IJ, Ekwueme DU, Stroud L et al (2006) Why do men choose one treatment over another?: a review of patient decision making for localized prostate cancer. Cancer 106(9):1865-1874. doi:10.1002/ cncr.21822

3. Kirkpatrick JP, Anscher MS (2005) Radiotherapy for locally recurrent prostate cancer. Clin Adv Hematol Oncol 3(12): 933-942

4. Sharifi N, Farrar WL (2006) Androgen receptor as a therapeutic target for androgen independent prostate cancer. Am J Ther 13(2):166-170. doi:10.1097/00045391-200603000-00013

5. Eder IE, Haag P, Bartsch G, Klocker $\mathrm{H}$ et al (2005) Targeting the androgen receptor in hormone-refractory prostate cancer-new concepts. Future Oncol 1(1):93-101. doi:10.1517/14796694. 1.1 .91

6. Trapman J, Brinkmann AO (1996) The androgen receptor in prostate cancer. Pathol Res Pract 192(7):752-760

7. Denmeade SR, Isaacs JT (2002) A history of prostate cancer treatment. Nat Rev Cancer 2(5):389-396. doi:10.1038/nrc801

8. Marcelli M, Ittmann M, Mariani S, Sutherland R, Nigam R, Murthy L et al (2000) Androgen receptor mutations in prostate cancer. Cancer Res 60(4):944-949 
9. Taplin ME, Bubley GJ, Ko YJ, Small EJ, Upton M, Rajeshkumar B et al (1999) Selection for androgen receptor mutations in prostate cancers treated with androgen antagonist. Cancer Res 59(11):2511-2515

10. Taplin ME, Rajeshkumar B, Halabi S, Werner CP, Woda BA, Picus $\mathrm{J}$ et al (2003) Androgen receptor mutations in androgen-independent prostate cancer: cancer and leukemia group B study 9663 . J Clin Oncol 21(14):2673-2678. doi:10.1200/JCO.2003.11.102

11. Tilley WD, Buchanan G, Hickey TE, Bentel JM et al (1996) Mutations in the androgen receptor gene are associated with progression of human prostate cancer to androgen independence. Clin Cancer Res 2(2):277-285

12. Feldman BJ, Feldman D (2001) The development of androgenindependent prostate cancer. Nat Rev Cancer 1(1):34-45. doi:10.1038/35094009

13. Vom Saal FS, Nagel SC, Timms BG, Welshons WV et al (2005) Implications for human health of the extensive bisphenol A literature showing adverse effects at low doses: a response to attempts to mislead the public. Toxicology 212(2-3):244-252. doi:10.1016/j.tox.2005.05.006

14. Gupta C (2000) Reproductive malformation of the male offspring following maternal exposure to estrogenic chemicals. Proc Soc Exp Biol Med 224(2):61-68. doi:10.1046/j.1525-1373.2000.22402.x

15. Timms BG, Howdeshell KL, Barton L, Bradley S, Richter CA, vom Saal FS et al (2005) Estrogenic chemicals in plastic and oral contraceptives disrupt development of the fetal mouse prostate and urethra. Proc Natl Acad Sci USA 102(19):7014-7019. doi:10.1073/pnas.0502544102

16. Thayer KA, Ruhlen RL, Howdeshell KL, Buchanan DL, Cooke PS, Preziosi D et al (2001) Altered prostate growth and daily sperm production in male mice exposed prenatally to subclinical doses of 17alpha-ethinyl oestradiol. Hum Reprod 16(5):988-996. doi:10.1093/humrep/16.5.988

17. Ralph JL, Orgebin-Crist MC, Lareyre JJ, Nelson CC et al (2003) Disruption of androgen regulation in the prostate by the environmental contaminant hexachlorobenzene. Environ Health Perspect 111(4):461-466

18. Ramos JG, Varayoud J, Sonnenschein C, Soto AM, Munoz De Toro M, Luque EH et al (2001) Prenatal exposure to low doses of bisphenol A alters the periductal stroma and glandular cell function in the rat ventral prostate. Biol Reprod 65(4):1271-1277. doi:10.1095/biolreprod65.4.1271

19. Ho SM, Tang WY, Belmonte de Frausto J, Prins GS et al (2006) Developmental exposure to estradiol and bisphenol A increases susceptibility to prostate carcinogenesis and epigenetically regulates phosphodiesterase type 4 variant 4 . Cancer Res 66(11):5624-5632. doi:10.1158/0008-5472.CAN-06-0516

20. Keri RA, Ho SM, Hunt PA, Knudsen KE, Soto AM, Prins GS et al (2007) An evaluation of evidence for the carcinogenic activity of bisphenol A. Reprod Toxicol 24(2):240-252. doi:10.1016/j.reprotox.2007.06.008

21. Prins GS, Birch L, Tang WY, Ho SM et al (2007) Developmental estrogen exposures predispose to prostate carcinogenesis with aging. Reprod Toxicol 23(3):374-382. doi:10.1016/j.reprotox. 2006.10.001

22. Herath CB, Jin W, Watanabe G, Arai K, Suzuki AK, Taya K et al (2004) Adverse effects of environmental toxicants, octylphenol and bisphenol $\mathrm{A}$, on male reproductive functions in pubertal rats. Endocrine 25(2):163-172. doi:10.1385/ENDO:25:2:163

23. Ogura Y, Ishii K, Kanda H, Kanai M, Arima K, Wang Y et al (2007) Bisphenol A induces permanent squamous change in mouse prostatic epithelium. Differentiation 75(8):745-756. doi: 10.1111/j.1432-0436.2007.00177.x

24. Hess-Wilson JK, Knudsen KE (2006) Endocrine disrupting compounds and prostate cancer. Cancer Lett 241(1):1-12. doi:10.1016/j.canlet.2005.10.006
25. Maffini MV, Rubin BS, Sonnenschein C, Soto AM et al (2006) Endocrine disruptors and reproductive health: the case of bisphenol-A. Mol Cell Endocrinol 254-255:179-186. doi:10.1016/ j.mce.2006.04.033

26. Prins GS (2008) Endocrine disruptors and prostate cancer risk. Endocr Relat Cancer 15(3):649-656. doi:10.1677/ERC-08-0043

27. Prins GS, Tang WY, Belmonte J, Ho SM et al (2008) Perinatal exposure to oestradiol and bisphenol A alters the prostate epigenome and increases susceptibility to carcinogenesis. Basic Clin Pharmacol Toxicol 102(2):134-138

28. Wetherill YB, Fisher NL, Staubach A, Danielsen M, de Vere White RW, Knudsen KE et al (2005) Xenoestrogen action in prostate cancer: pleiotropic effects dependent on androgen receptor status. Cancer Res 65(1):54-65

29. Wetherill YB, Petre CE, Monk KR, Puga A, Knudsen KE et al (2002) The xenoestrogen bisphenol A induces inappropriate androgen receptor activation and mitogenesis in prostatic adenocarcinoma cells. Mol Cancer Ther 1(7):515-524

30. Shah S, Hess-Wilson JK, Webb S, Daly H, Godoy-Tundidor S, Kim J et al (2008) 2, 2-Bis(4-chlorophenyl)-1, 1-dichloroethylene stimulates androgen independence in prostate cancer cells through combinatorial activation of mutant androgen receptor and mitogen-activated protein kinase pathways. Mol Cancer Res 6(9):1507-1520. doi:10.1158/1541-7786.MCR-07-2166

31. Kang JH, Kondo F, Katayama Y et al (2006) Human exposure to bisphenol A. Toxicology 226(2-3):79-89. doi:10.1016/j.tox. 2006.06.009

32. Tsai WT (2006) Human health risk on environmental exposure to Bisphenol-A: a review. J Environ Sci Health C Environ Carcinog Ecotoxicol Rev 24(2):225-255

33. vom Saal FS, Hughes C (2005) An extensive new literature concerning low-dose effects of bisphenol A shows the need for a new risk assessment. Environ Health Perspect 113(8):926-933

34. Munguia-Lopez EM, Soto-Valdez H (2001) Effect of heat processing and storage time on migration of bisphenol A (BPA) and bisphenol A-diglycidyl ether (BADGE) to aqueous food simulant from Mexican can coatings. J Agric Food Chem 49(8):36663671. doi:10.1021/jf0009044

35. Munguia-Lopez EM, Gerardo-Lugo S, Peralta E, Bolumen S, Soto-Valdez H et al (2005) Migration of bisphenol A (BPA) from can coatings into a fatty-food simulant and tuna fish. Food Addit Contam 22(9):892-898. doi:10.1080/026520305001 63674

36. Yoshida T, Horie M, Hoshino Y, Nakazawa H et al (2001) Determination of bisphenol A in canned vegetables and fruit by high performance liquid chromatography. Food Addit Contam 18(1):69-75. doi:10.1080/026520301446412

37. Brede C, Fjeldal P, Skjevrak I, Herikstad H et al (2003) Increased migration levels of bisphenol A from polycarbonate baby bottles after dishwashing, boiling and brushing. Food Addit Contam 20(7):684-689. doi:10.1080/0265203031000119061

38. Calafat AM, Kuklenyik Z, Reidy JA, Caudill SP, Ekong J, Needham LL et al (2005) Urinary concentrations of bisphenol A and 4-nonylphenol in a human reference population. Environ Health Perspect 113(4):391-395

39. Welshons WV, Nagel SC, vom Saal FS et al (2006) Large effects from small exposures. III. Endocrine mechanisms mediating effects of bisphenol A at levels of human exposure. Endocrinology 147(6 (suppl)):S56-S69. doi:10.1210/en.2005-1159

40. Horoszewicz JS, Leong SS, Chu TM, Wajsman ZL, Friedman M, Papsidero L et al (1980) The LNCaP cell line-a new model for studies on human prostatic carcinoma. Prog Clin Biol Res $37: 115-132$

41. Horoszewicz JS, Leong SS, Kawinski E, Karr JP, Rosenthal H, Chu TM et al (1983) LNCaP model of human prostatic carcinoma. Cancer Res 43(4):1809-1818 
42. Gaddipati JP, McLeod DG, Heidenberg HB, Sesterhenn IA, Finger MJ, Moul JW et al (1994) Frequent detection of codon 877 mutation in the androgen receptor gene in advanced prostate cancers. Cancer Res 54(11):2861-2864

43. Wetherill YB, Hess-Wilson JK, Comstock CE, Shah SA, Buncher CR, Sallans L et al (2006) Bisphenol A facilitates bypass of androgen ablation therapy in prostate cancer. Mol Cancer Ther 5(12):3181-3190. doi:10.1158/1535-7163.MCT-06-0272

44. Matthews JB, Twomey K, Zacharewski TR et al (2001) In vitro and in vivo interactions of bisphenol $\mathrm{A}$ and its metabolite, bisphenol A glucuronide, with estrogen receptors alpha and beta. Chem Res Toxicol 14(2):149-157. doi:10.1021/tx0001833

45. Snyder RW, Maness SC, Gaido KW, Welsch F, Sumner SC, Fennell TR et al (2000) Metabolism and disposition of bisphenol A in female rats. Toxicol Appl Pharmacol 168(3):225-234. doi:10.1006/taap.2000.9051

46. Hess-Wilson JK, Webb SL, Daly HK, Leung YK, Boldison J, Comstock CE et al (2007) Unique bisphenol A transcriptome in prostate cancer: novel effects on ERbeta expression that correspond to androgen receptor mutation status. Environ Health Perspect 115(11):1646-1653

47. Li L, Andersen ME, Heber S, Zhang Q et al (2007) Non-monotonic dose-response relationship in steroid hormone receptormediated gene expression. J Mol Endocrinol 38(5):569-585. doi:10.1677/JME-07-0003

48. Pravettoni A, Mornati O, Martini PG, Marino M, Colciago A, Celotti $\mathrm{F}$ et al (2007) Estrogen receptor beta (ERbeta) and inhibition of prostate cancer cell proliferation: studies on the possible mechanism of action in DU145 cells. Mol Cell Endocrinol 263(1-2):46-54. doi:10.1016/j.mce.2006.08.008

49. Maggiolini M, Recchia AG, Carpino A, Vivacqua A, Fasanella G, Rago V et al (2004) Oestrogen receptor beta is required for androgen-stimulated proliferation of $\mathrm{LNCaP}$ prostate cancer cells. J Mol Endocrinol 32(3):777-791. doi:10.1677/jme.0. 0320777

50. Horvath LG, Henshall SM, Lee CS, Head DR, Quinn DI, Makela $S$ et al (2001) Frequent loss of estrogen receptor-beta expression in prostate cancer. Cancer Res 61(14):5331-5335
51. Ji Q, Liu PI, Elshimali Y, Stoltz A et al (2005) Frequent loos of estrogen and progesterone receptors in human prostatic tumors determined by quantitative real-time PCR. Mol Cell Endocrinol 229(1-2):103-110. doi:10.1016/j.mce.2004.08.012

52. Lai JS, Brown LG, True LD, Hawley SJ, Etzioni RB, Higano CS et al (2004) Metastasis of prostate cancer express estrogen receptor-beta. Urology 64(4):814-820. doi:10.1016/j.urology. 2004.05.036

53. Leav I, Lau KM, Adams JY, McNeal JE, Taplin ME, Wang J et al (2001) Comparative studies of the estrogen receptors beta and alpha and the androgen receptor in normal human prostate glands, dysplasia, and in primary and metastatic carcinoma. Am J Pathol 159(1):79-92

54. Hess-Wilson JK, Boldison J, Weaver KE, Knudsen KE et al (2006) Xenoestrogen action in breast cancer: impact on ERdependent transcription and mitogenesis. Breast Cancer Res Treat 96(3):279-292. doi:10.1007/s10549-005-9082-y

55. Nabholtz JM, Buzdar A, Pollak M, Harwin W, Burton G, Mangalik A et al (2000) Anastrozole is superior to tamoxifen as firstline therapy for advanced breast cancer in postmenopausal women: results of a North American multicenter randomized trial. Arimidex study group. J Clin Oncol 18(22):3758-3767

56. Ingle JN, Suman VJ (2003) Aromatase inhibitors versus tamoxifen for management of postmenopausal breast cancer in the advanced disease and neoadjuvant settings. J Steroid Biochem Mol Biol 86(3-5):313-319. doi:10.1016/S0960-0760(03)00373$\mathrm{X}$

57. Arora A, Potter JF (2004) Aromatase inhibitors: current indications and future prospects for treatment of postmenopausal breast cancer. J Am Geriatr Soc 52(4):611-616. doi:10.1111/j.15325415.2004.52171.x

58. Allred DC, Mohsin SK (2000) Biological features of premalignant disease in the human breast. J Mammary Gland Biol Neoplasia 5(4):351-364. doi:10.1023/A:1009573710675

59. La Pensee EW, Tuttle TR, Fox SR, Ben-Johnathan N (2009) Bisphenol A at low nanomolar doses confers chemoresistance in estrogen receptor alpha positive and negative breast cancer cells. Environ Health Perspect 117(2):175-180. doi:10.1289/ehp.11788 